\title{
Emotion recognition abilities and empathy of victims of bullying
}

3 a University of Hertfordshire, School of Psychology, Hatfield, UK

$4 \mathbf{Q 1}$ b University of Warwick, Department of Psychology and Warwick Medical School, Coventry CV4 7AL, UK

Emory University, Department of Psychology, Atlanta, GA, USA
University of Sunderland, School of Computing $\mathcal{E}$ Techitology, University of Sunderland, Sunderland, UK

\section{A R T I C L E I N F O}

\section{Article history:}

Received 8 August 2007

Received in revised form

20 November 2008

Accepted 26 November 2008

Available online xxx

\section{Keywords:}

Victimisation

Emotionrecognition

Empathy

Q2 Social-information processing

Bullying behaviour is a common experience for a significant minority of children and adolescents. Bullying is the sys- $\mathbf{Q}^{3}$ tematic abuse of power among peers or siblings (Sharp \& Smith, 1994, p. 2; Wolke \& Samara, 2004), with adverse effects on mental health in a significant number of victims (Stassen Berger, 2007). Physical bullying is characterised by observable, externalised behaviours including being hit or beaten up, physical threats, blackmail, and nasty tricks. In contrast, relational forms of victimisation include more subtle indirect forms of behaviour including friendship withdrawal, untrue rumours, and social exclusion. Crick and colleagues argued that physical and relational behaviours loaded onto separate factors (Crick \& Grotpeter, 1995), while some argue that there is some overlap between physical, and relational forms of bullying (e.g., Archer \& Coyne, 2005). Therefore, it is increasingly important to consider the possible overlap between physical and relational bullying.

The Social Information Processing Theory (SIP) offers a detailed six-stage model of how children process and interpret cues in social situations to arrive at competent behaviour (e.g., Crick \& Dodge, 1994). Previous SIP research has concentrated on the biases and deficits that aggressors use in social situations, and has not considered in detail the SIP styles of victims. In particular, little is known about the role of emotions and emotion recognition within a SIP framework. This has several implications both for victimisation and bullying perpetration. Being able to perceive and attribute emotions correctly is important for a child's social and cognitive development (e.g., Nowicki \& Duke, 1994). How children become involved in various physical and relational bullying roles may be related to how well they are able to interpret the emotional states of their peers. Previous associations between victimisation and poor social skills (e.g., Fox \& Boulton, 2005) have been reported, but it remains unknown whether this is related to problems recognising and interpreting emotional information (Stassen

\footnotetext{
This research was conducted as part of the VICTEC project (IST-2001-33310) (www.victec.org), part-funded by the European Community Framework $\checkmark$ Program.

* Corresponding author.
} 
Berger, 2007). The manipulation of social relationships (i.e., relational victimisation) is dependent on the ability of the bully perpetrator to successfully identify the social and emotional weaknesses of specific individuals (e.g., Arsenio \& Lemerise, 2001). In contrast, physical victimisation may rely more on identifying that the potential victim is physically weaker and has few friends who could support him (Wolke \& Stanford, 1999).

The empathic styles of bullies and victims may also differ, and there is controversy about whether bullies are socially skilled cool manipulators who are unable to empathise with others (Dautenhahn, Woods, \& Kaouri, 2007), or just deficient in their social skills (e.g., Crick \& Dodge, 1994). The SIP model emphasises social deficits, however effective bullying, and in particular relational bullying requires sophisticated social and emotional skills to manipulate the victim, and the peer group network into accepting their behaviour (Sutton, 2001). This would suggest that relational bullies do not differ from others in their perception of emotions, but rather in how to use them, by cognitively minimising or distorting the amount of distress felt by the victim (Arsenio \& Lemerise, 2001).

The present study tested whether victims, in general, have poorer emotion recognition abilities compared to bullies and neutral children (not involved in bullying perpetration or victimisation). Specifically, it was expected that relational victims and "overlap" victims (victims of physical and relational bullying acts) would have poorer emotion recognition abilities compared to physical victims, as competent emotion recognition skills are more important for relational bullying that is centred on the manipulation of close relationships. Secondly, it was hypothesised that bullies would have the lowest levels of empathy compared to victims and neutrals.

\section{Method}

\section{Participants}

Overall, 373 primary school children from 11 schools in Hertfordshire, UK participated in the study, aged 9-11 years $(M=9.94, S D=0.45)$. Of the 373 children, 200 children had full datasets (i.e., bullying nominations, DANVA and Empathy Questionnaire). Sixteen schools were approached via telephone to take part in the study (69\% overall participation). The average school size was 192 (range: 100-240 pupils). A total of $9 \%$ of children came from ethnic minority groups. If a school was interested in taking part, information letters and parental consent letters were distributed to the relevant teachers. Overall parental consent for their child's participation in the study was $97 \%$.

\section{Instruments}

Bullying nominations. Using a time frame of the previous 6 months, children were asked to indicate up to 6 children in their class they believed physically bullied other children, and up to 6 children they thought were physically victimised (hit/beaten up, belongings stolen, threats, blackmail, nasty tricks). The same procedure was used to assess relational bullying (getting called nasty names, being deliberately left out of games, withdrawal of friendship, and nasty rumour spreading). Each child in the class was represented by a unique number and recorded. The accuracy of recording compared to names was double checked and exceeded $98 \%$. The description of physical and relational bullying behaviours was adapted from Wolke, Woods, Bloomfield, \& Karstadt (2000).

Children were classified into physical bullying and relational bullying roles: physical bullies (nominated by 3 or more children in the class as being involved in physically bullying others, but did not receive any peer nominations for being victimised); physical victims (nominated by 3 or more children in the class as being physically victimised and received no peer nominations for physically bullying others); physical bully/victims (nominated on 3 or more occasions by peers as both physically bullying others and being physical victims); physical neutrals who neither physically bullied others nor became physical victims (received no, or less than 3 peer nominations for physically bullying others or being victimised). For relational bu介lying the same classification system was employed. All peer nominations were standardised by class to account for differences in class size. Involvement in both physical and relational bullying was determined: physical bully only, relational bully only, physical and relational bully, physical victim only, relational victim only, physical and relational victim.

DANVA (Diagnostic Analysis of Nonverbal Accuracy) (Nowicki, 2005). The child facial expression test is a computerised test consisting of 24 photographs ( 12 male, 12 female, and mixed ethnicity) equally distributed between high and low intensity expressions of four emotions; happy, sad, angry and fearful. Happy, sad, angry, and fearful response options appeared on the screen below each photo. Each photo appeared on the computer screen for two seconds. Tests have shown the DANVA to have high internal consistency (current sample alpha $=.61$ indicating moderate internal consistency), and that it is reliable over time (test-re-test reliabilities between .70 and .80 over $6-8$ week periods). Construct validity support is also evident from results of over 200 studies with age ranges from 3 to 80 years (Nowicki, 2005).

Bryant index of empathy measurement for children and adolescents. Empathy styles were measured using Bryant (1982) 22item empathy index (example items "When I see someone who is feeling upset, I think about why he might be feeling like that", "Seeing someone who is crying makes me feel like crying"). The index focuses specifically on affective components of the empathic process. The response format was changed from the original two-stage (yes vs. no responses) format that 
Bryant used, to a scale of one "I strongly agree" to five "I strongly disagree". Cronbach alpha for the current sample was .70 indicating moderate internal consistency.

\section{Procedure}

Ethical permission to complete the study was obtained from the University of Hertfordshire Ethical Committee. Written information about the study and a non-consent form (parents were asked to sign if they did not want their child to participate) was passed to all parents. The study took place at the University of Hertfordshire as part of an evaluation for a new antibullying software programme. A clear distinction between physical and relational bullying was provided before questionnaire completion. Children were ensured of their confidentiality and that they could withdraw from the study at any point. Children completed the Bullying Nominations assessment followed by the Bryant's Empathy Index. Children completed the DANVA following a short break after the software interaction.

\section{Results}

Incidence of peer-nominated bullying roles

Of those children involved in some form of bullying behaviour $(n=141), 30.5 \%$ were classified as physical and relational victims, followed by $24.1 \%$ as physical and relational bullies. Pure bullying roles were less frequent with $15.6 \%$ of children classified as physical victims only, $12.8 \%$ as relational victims only, $9.2 \%$ as physical bullies only, and $7.8 \%$ as relational bullies only. A Kappa coefficient (Kappa $=0.64, p<.001$ ), indicated a significant amount of overlap between physical and relational bullying roles. The analytical framework included distinct physical and relational victimisation roles, "overlap" victims (children peer nominated as both physical and relational victims), and "neutrals".

\section{Overall emotion recognition abilities}

Overall mean error rates on the DANVA emotion recognition test revealed that children made the fewest errors for "happy" $(M=.71, S D=1.12)$, followed by "sad" $(M=1.00, S D=1.35)$, "fear" $(M=2.05, S D=1.62)$, and the highest mean error rate was found for "anger" $(M=2.73, S D=1.57)$.

Emotion recognition abilities and gender

A number of significant differences emerged between gender and emotion recognition abilities. Boys made significantly more mean total errors on the DANVA compared to girls, $t=2.93$, (284), $p=.004$ (boys $M=7.56$, girls $M=6.03$ ). When each emotion was analysed individually, boys made significantly more mean total errors for happy, $t=2.61,(284), p=.01$ (boys $M=.90$, girls $M=.55$ ), anger, $t=2.89$, (284), $p=.004$ (boys $M=3.06$, girls, $M=2.51$ ) and fear, $t=2.47$, (284), $p=.01$ (boys $M=2.31$, girls $M=1.84$ ).

\section{Emotion recognition abilities and peer-nominated physical and relational victimisation status}

Total errors on DANVA. An ANCOVA (controlled for by gender) revealed no significant differences between physical bullying roles and mean number of total errors made on the DANVA, $F(2,263)=.42, p=.66$. No other significant differences between physical bullying roles and DANVA, for specific emotions were found throughout the analysis.

A number of significant differences were uncovered between relational victimisation status and DANVA scores for total errors and individual emotions (Table 1). Relational victims, and in some cases "overlap" victims were significantly poorer at emotion recognition abilities on the DANVA compared to neutral children.

ANCOVA for victimisation role and total DANVA errors, controlling for gender was significant $F(2,200)=3.52$, $p=.03(d=.04)$. Planned ${ }^{\circ}$ ost hoc comparisons indicated that "pure" relational victims $t(167)=2.26, p=.03$, and "over-

Table 1

Mean number $(S D)$ of errors made for relational victimisation roles on DANVA Emotion Recognition test $(N=200)$.

\begin{tabular}{|c|c|c|c|c|}
\hline & \multicolumn{3}{|c|}{ Relational Victimisation Status } & \multirow[b]{2}{*}{ F statistic } \\
\hline & Pure relational victim $(n=11)$ & Relational \& Physical Victim (Overlap) ( $n=31$ ) & Neutral $(n=158)$ & \\
\hline Total DANVA Errors* & $9.18(3.76)$ & $8.13(5.12)$ & $6.22(4.22)$ & 3.52 \\
\hline Happy DANVA Errors (ns) & $.73(1.10)$ & $.97(1.38)$ & $.68(1.06)$ & 0.41 \\
\hline Sad DANVA Errors (ns) & $1.64(1.50)$ & $1.39(1.75)$ & $.93(1.20)$ & 2.51 \\
\hline Angry DANVA Errors*" & $3.91(1.14)$ & $3.10(1.76)$ & $2.58(1.53)$ & 5.73 \\
\hline Fear DANVA Errors* ${ }^{*}$ & $2.82(1.66)$ & $2.52(1.81)$ & $1.84(1.57)$ & 3.03 \\
\hline
\end{tabular}

Note: Overall significance levels are shown. Individual post hoc differences between bullying roles are shown in the text. $p=.05$. 
lap" victims $t(187)=2.22, p=.03$ made significantly more mean total errors on the DANVA compared to neutrals (Table 1).

Recognition of individual emotions (happy, sad, anger, fear) and relational victimisation status

No significant differences were found for relational victimisation roles, and mean number of errors for happy and sad emotions on the DANVA. ANCOVA (gender controlled) between relational victimisation and mean errors for angry emotions was significant $F(2,200)=5.73, p=.02(d=.04)$. Post hoc planned comparisons revealed that 'pure' relational victims made significantly more errors for angry faces on the DANVA compared to neutrals $t(167)=2.82, p=.005$ (Table 1 ). A similar pattern of findings emerged for faces that depicted fear emotions on the DANVA, for relational victimisation status $F(2,200)=3.03$, $p=.05(d=.04)$. "Pure" relational victims $t(167)=1.99, p=.05)$, and "overlap" victims $t(187)=2.13, p=.03$ made more errors compared to neutrals (Table 1 ).

Bullying roles and association with Bryant empathy scores

An Independent measures $t$-test revealed that boys had significantly lower empathy scores compared to girls $t=-4.40$, (242), $p<.001$ (boys: $M=47.88$, girls: $M=53.60$ ). ANCOVA between bullying roles, for Bryant empathy scores controlling for gender revealed no significant differences $F(2,184)=2.04, p=.13$.

\section{Association between emotion recognition abilities and Bryant empathy scores}

The mean overall score on the Bryant Empathy Scale was 50.99 ( $S D=10.67$; range 26-77). No significant relationship between overall emotion recognition abilities and empathy scores was found $r=-.10, p=.13$. Only one significant negative correlation was found between total Bryant empathy scores and emotion recognition scores for fear $r=-.14\left(r^{2}=.02\right), p=.03$. This indicates that higher empathy scores were associated with lower errors rates for recognising fear emotions. However, despite the statistical significance, this is likely to be an unreliable effect due to the low variance accounted for, and the small sample size.

\section{Discussion}

The hypothesis that victims, in general, would have poorer emotion recognition abilities could not be accepted as physical victims were not found to have poorer abilities compared to neutrals and bullies. In contrast, some support was generated for the hypothesis that relational victims would have poor emotion recognition abilities. Relational victims and in some instances “overlap" victims (both relational and physical victims) were not as adept as others at recognising emotions overall, and more specifically in faces depicting angry and fear emotions. However, the effect sizes for differences in emotion recognition abilities were small.

Poor emotion abilities shown by relational victims may be one of the contributors to why they are repeated targets of victimisation by peers at school. Relational victimisation relies heavily on understanding the dynamics of the peer group and the subtle manipulation of social behaviour. The current results provide some initial support that the SIP model could provide a useful framework to further understand the social processing abilities of victims. Relational victims appear to have problems at the initial stages of the model with the correct encoding of cues, and the interpretation of cues (Crick \& Dodge, 1994). These problems could in turn lead them to make incorrect judgments of the motivations of others, have poor access to appropriate responses and, ultimately, to make poor action decisions (Camodeca, Goossens, Schuengel, \& Terwogt, 2003). However, the current results cannot say anything about the causal pathways.

The hypothesis that bullies would demonstrate the lowest levels of empathy compared to victims and neutral children was not supported. This was a surprising result as some previous findings have reported that those involved in frequent bullying have lower levels of affective empathy, but not cognitive empathy (e.g., Jolliffe \& Farrington, 2006). Affective empathy does depend on the seriousness of the bullying (e.g., physical attacks). Perhaps the current bullying assessment did not adequately distinguish between serious attacks and lower level bullying forms. Furthermore, the questionnaire may not have been sensitive enough to access the affective component of empathy. Physiological or observational assessments may be required to accurately measure empathic styles.

Further research involving a larger and more balanced sample of children is warranted in light of several methodological shortcomings of the current study. Limitations include the small effect sizes found between relational victims and emotion recognition abilities, and no information was collated about the socio-economic status of the sample. This could compromise the external validity of the findings. Furthermore, the sample size of 200 children was relatively small, resulting in some of the groups for the statistical analysis being highly unequal.

Future work should address emotional processing at different levels during information processing to determine whether there is a consistent pattern of deficits for children who are victimised. The current study does not relate emotion recognition abilities to further information processing or the ability to perspective take (e.g., theory of mind) (Sutton, Smith, \& Swettenham, 1999). The link between emotion recognition and the understanding of other's perspectives in emotionally charged situations requires future exploration. 
The current results suggest that emotion recognition training may be beneficial for relational victims as part of a package of interventions, and could have a positive impact on other relationships.

\section{Acknowledgements}

We would like to thank all the VICTEC team members for making this study possible. Special thanks also to all the schools in Hertfordshire that took part.

\section{References}

Archer, J., \& Coyne, S. M. (2005). An integrated review of indirect, relational and social aggress. Personality and Social Psychology Review, 9, 212-230. Arsenio, W. F., \& Lemerise, E. A. (2001). Varieties of childhood bullying: Values, emotion processes and social competence. Social Development, 10(1), 59-73. Bryant, B. K. (1982). An index of empathy for children and adolescents. Child Development, 53(1), 413-425.

Camodeca, M., Goossens, F. A., Schuengel, C., \& Terwogt, M. M. (2003). Links between social informative processing in middle childhood and involvement in bullying. Aggressive Behavior, 29(2), 116-127.

Crick, N. R., \& Dodge, K. A. (1994). A review and reformulation of social information-processing mechanisms in children's social adjustment. Psychological Bulletin, 115(1), 74-101.

Crick, N. R., \& Grotpeter, J. K. (1995). Relational aggression, gender, and social-psychological adjustment. Child Development, 66, 710-722.

Dautenhahn, K., Woods, S., \& Kaouri, C. (2007). Possible connections between bullying behaviour, empathy and imitation. In K. Dautenhahn, \& C. Nehaniv (Eds.), Models and mechanisms of imitation and social learning in robots, humans and animals: Behavioural social and communicative dimensions (pp. 323-339). Cambridge: Cambridge University Press.

Fox, C. L., \& Boulton, M. J. (2005). The social skills of victims of bullying: Self, peer and teacher perceptions. British Journal of Educational Psychology, 75, $313-328$.

Jolliffe, D., \& Farrington, D. P. (2006). Examining the relationship between low empathy and bullying. Aggressive Behavior, 32, 540-550.

Nowicki, S. J. (2005). The manual for the Diagnostic Analyses of Nonverbal Accuracy (DANVA) tests. Atlanta, GA: Department of Psychology, Emory University. Nowicki, S., Jr., \& Duke, M. P. (1994). Individual differences in nonverbâl communication of effect: The diagnostic analysis of nonverbal accuracy scale (DANVA). Journal of Nonverbal Behaviour, 18, 9-35.

Sharp, S., \& Smith, P. K. (Eds.). (1994). Tackling bullying in your school. London: Routledge.

Stassen Berger, K. (2007). Update on bullying at school: A science forgotten? Developmental Review, 27, 90-126.

Sutton, J. (2001). Bullies: Thugs or thinkers? The Psychologist, 14(10), 530-534.

Sutton, J., Smith, P. K., \& Swettenham, J. (1999). Bullying and 'theory of mind': A critique of the 'social skills deficit' view of anti-social behaviour. Social Development, 8(1), 117-127.

Wolke, D., \& Samara, M. (2004). Bullied by siblings: Association with peer victimisation and behaviour problems in Israeli lower secondary school children. Journal of Child Psychology and Psychiatry, 45(5), 1015-1029.

Wolke, D., \& Stanford, K. (1999). Bullying in school children. In D. Messer, \& S. Millar (Eds.), Developmental psychology (1st ed., pp. 341-360). London: Arnold Publisher.

Wolke, D., Woods, S., Bloomfield, L., \& Karstadt, L. (2000). The association between direct and relational bullying and behaviour problems among primary school children. The Journal of Child Psychology and Psychiatry, 41(8), 989-1002. 